
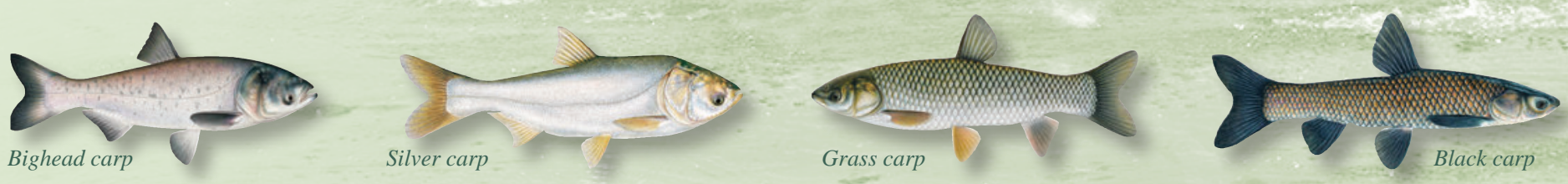

\title{
USGS Science and Technology Help Managers Battle Invading Asian Carp
}

\section{The USGS delivers high-quality data, technologies, and decision-support tools to help managers reduce existing populations and control the spread of Asian carp in the Nation's waterways.}

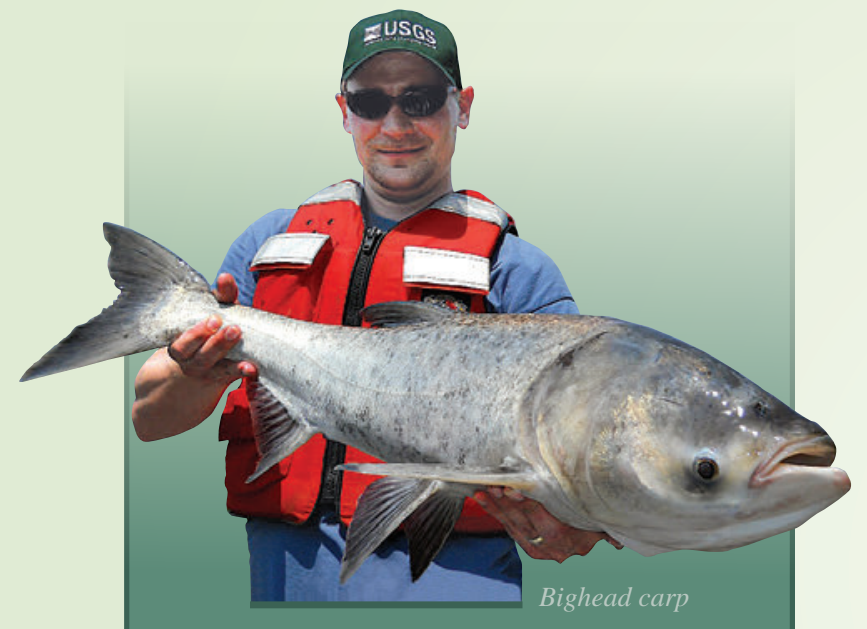

What are Asian Carp?

The term "Asian carp" is used here to refer to four species of fish introduced into the United States in the 1960s and 1970s. Asian carp now have reproducing populations in waters of the United States. These species have similar life histories but differ in diet and distribution. Bighead carp and silver carp are filter feeders that remove plankton from the water and are established throughout much of the Mississippi River Basin. Grass carp specialize on eating submerged aquatic plants and are widely distributed in the United States, with growing numbers of reproducing populations, including in the Lake Erie watershed. Black carp consume freshwater mussels, snails, and other mollusks and have a limited but expanding range in the Mississippi River.
The U.S. Geological Survey (USGS) conducts Asian carp research focused on early detection, risk assessment, and development of control tools and strategies. The goals are to prevent the establishment of invasive Asian carp in the Great Lakes and to reduce their impacts in the Ohio River and Mississippi River Basins and elsewhere. Managers can use the information, tools, and strategies for early detection of Asian carp and to control them when their presence is first evident. New detection and control tools are designed to accommodate expansion to other invasive species and application in geographically diverse areas.

This USGS focus complements goals of the Great Lakes Restoration Initiative (GLRI), a multi-agency collaboration started in 2010 to protect and restore the Great Lakes. As a member of the Asian Carp Regional Coordinating Committee, which guides Asian carp efforts, the USGS works closely with Federal and State agencies, Canada, and others to address high-priority Asian carp issues and provide science to inform management decisions.

The USGS has gained extensive knowledge of Asian carp biology and life history over the past 30 years. That knowledge guides the design, development, and application of control strategies,

and is essential for developing approaches in line with modern principles and practices of integrated pest management (IPM). IPM is a process used to solve pest problems while minimizing risks to people and the environment.

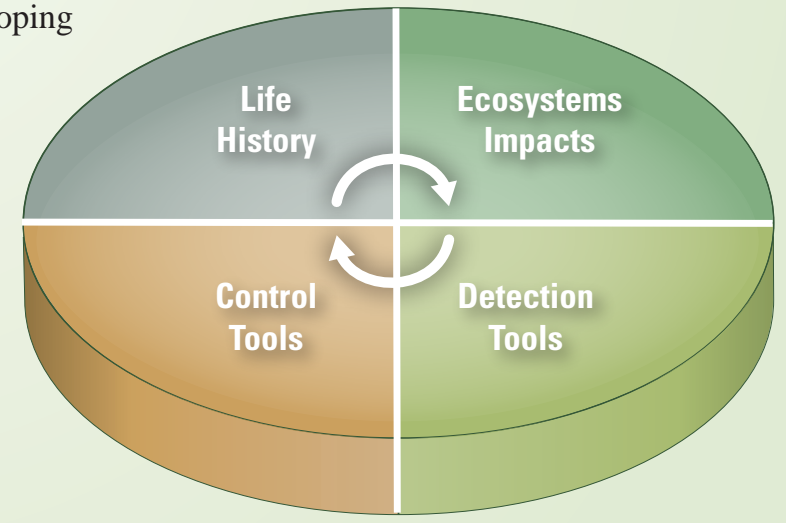

Use of an integrated pest management approach helps managers focus monitoring and control efforts. These multiple areas of research are interrelated. 


\section{Early Detection}

Early detection is a vital part of managing any invasive species. Detection of Asian carp is difficult because they avoid nets and other traditional capture gear, so they are hard to catch especially when populations are small. The USGS has contributed to the development and improvement of new genetic approaches to detect Asian carp at low abundances and identify initial invasions.

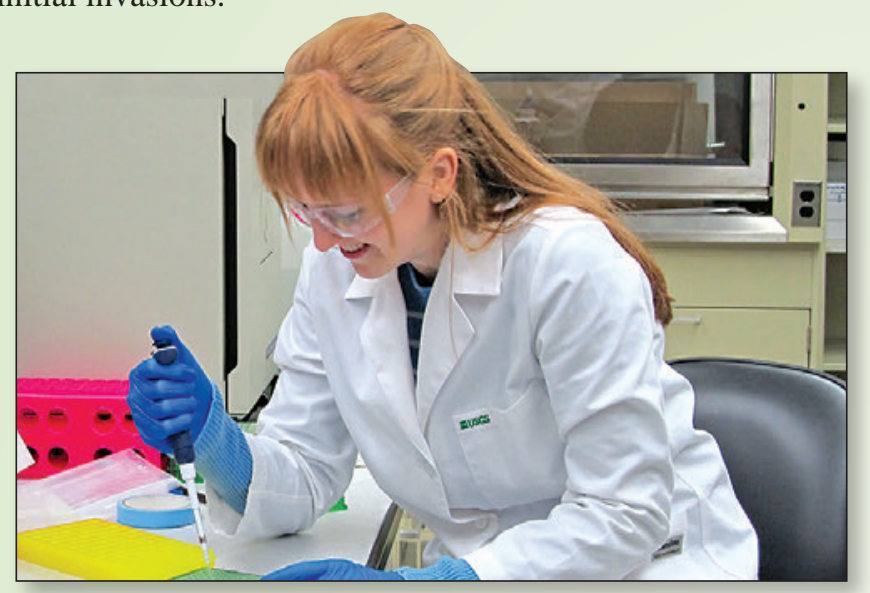

Samples containing environmental DNA are processed in a laboratory.

\section{Environmental DNA}

Improvements in the technology to detect environmental DNA (eDNA) offer the potential to provide managers a "genetic toolbox" for detection and characterization of Asian carp occurrence. This technology involves detection of DNA in an environmental sample, such as lake or river water. USGS research has led to refinements to past methods to improve detection sensitivity, increase cost-effectiveness, and decrease time between sampling and results. Current research efforts are focused on evaluating the application of eDNA detection as a tool to detect fish movement, habitat use, and spawning, and to evaluate the effectiveness of management actions. The USGS also is developing methods to use eDNA to estimate Asian carp biomass and to characterize how eDNA changes with the passage of time once shed from a live fish.

\section{Portable eDNA Detection Device}

Working with industry, the U.S. Fish and Wildlife Service (USFWS), and state agencies, the USGS has tested and validated a commercially available kit for rapid detection of Asian carp using eDNA. The portable kit reduces the time between sample collection and results from days to less than 1 hour for time-critical samples. Field testing indicates that lawenforcement officers without any prior experience can use the kit to detect the presence of a single, minnow-sized silver carp commingled with more than 10,000 fathead minnows in a large fish tank. Additional testing and accompanying directions and protocols for sample collection are being developed. Training and equipping law-enforcement officers with detection kits available through the GLRI is planned.

\section{Risk Assessment}

Scientists do risk assessments to estimate the likelihood a species may invade, spread, or cause economic or ecological damage; to identify ecosystems or habitats most likely to be invaded; and to

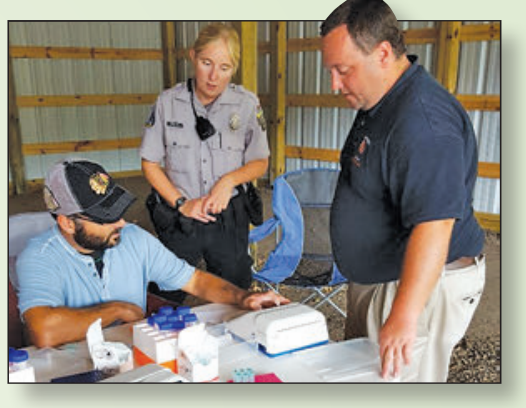

Law enforcement processing eDNA samples. estimate other risks associated with species' invasions. Risk assessments are part of the IPM process and help managers focus monitoring and control efforts. The USGS has worked with the Government of Canada on a completed international bighead carp and silver carp risk assessment and is part of a partnership developing assessments for grass carp and black carp. The USGS also strives to inform and support decision-makers by producing easy-to-use decision tools based on risk-assessment results.

\section{Identification of Potential Spawning Sites}

Understanding when Asian carp might be able to reproduce would inform monitoring and control efforts. Because not all habitats are suitable for reproduction, the USGS developed a computer model called Fluvial Egg Drift Simulator (FluEgg) to predict where river conditions would allow bighead, silver, and grass carp eggs and larval fish to survive until they find nursery habitat (fig. 1). FluEgg also can be used to assess risk of establishment of new spawning populations and to evaluate the effectiveness of control measures. It is applicable in areas where Asian carp are present and areas that have not yet been invaded. Identifying potential spawning areas may also provide opportunities for managers to disrupt spawning.

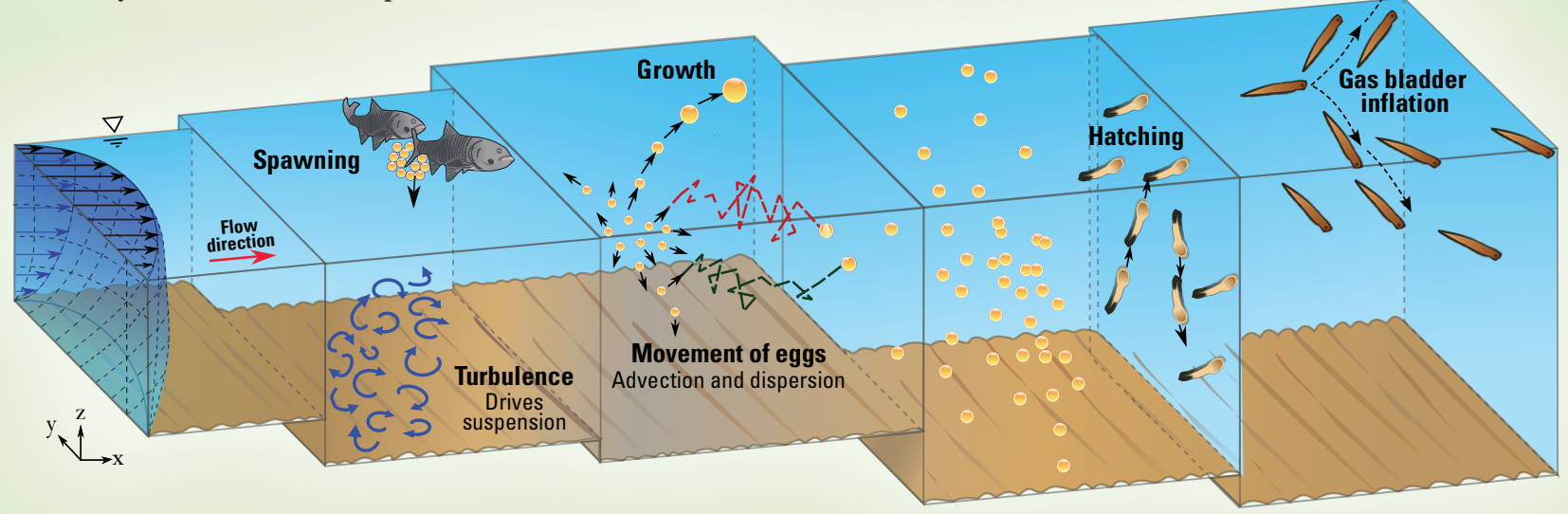

Figure 1. Conceptual schematic showing the Fluvial Egg Drift Simulator model and processes. (From Murphy and others, 2016.) 


\section{Assessment of Food Availability in the Great Lakes}

Understanding the potential impact of Asian carp in areas not yet invaded requires determining if adequate food resources are available. Using satellite imagery, USGS scientists have determined that there is enough food available for bighead carp and silver carp to survive if they reached Lake Erie. Green algae and blue-green algae on the surface of the lake are a preferred food source for these fish. The water temperatures and algal concentrations detected in Lake Erie from 2002 to 2011 show that bighead carp and silver carp could live and grow in this environment. If bighead carp and silver carp were to populate Lake Erie, they could damage native fish populations and have negative effects on the economy of the Great Lakes Region. Scientists also have begun to inventory and map aquatic vegetation in Lake Erie to better understand availability of food for grass carp.

\section{Integrated Containment and Control}

USGS scientists continue to develop and test containment and control tools and technologies to enhance the ability of agencies to manage Asian carp to minimize their influence and spread. The USGS also is investigating options for combined implementation of tools in an IPM context. A variety of control options, including hot water, ozone, and those mentioned below, have or are being explored, sometimes in creative combinations to address Asian carp issues.

\section{Preventing Movement toward the Great Lakes}

In collaboration with the U.S. Army Corps of Engineers (USACE), the USGS continues to collect

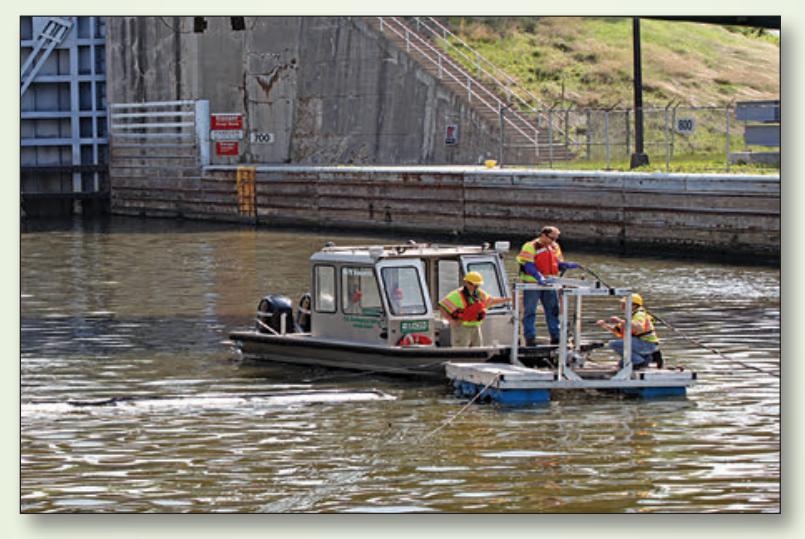

USGS scientists measuring flow velocity in a lock channel.
$\left(\mathrm{CO}_{2}\right)$. This has led the USGS to explore the use of elevated $\mathrm{CO}_{2}$ to deter the further spread of Asian carp in certain areas, such as above locks and dams. For example, the USGS is evaluating the behavior of Asian carp in $\mathrm{CO}_{2}$ gradients in the field and testing methods to deliver $\mathrm{CO}_{2}$. Research results show elevated $\mathrm{CO}_{2}$ can be an effective deterrent for bighead carp and silver carp that could be integrated with multiple deterrents and barriers (for example, electric, sound, and $\mathrm{CO}_{2}$ ) to provide control and redundancy.

\section{Microparticles}

The USGS is developing a targeted toxicant-delivery system in the form of a multilayered microparticle that is sized in the feeding range of bighead carp and silver carp but smaller than what most native fish feed on. The initial chemical incorporated into microparticles is Antimycin A, a U.S. Environmental Protection Agency (EPA)-registered fish toxicant, but the formulation of the particle can be modified to incorporate other potential fish-control chemicals. In laboratory studies, Asian carp consumed Antimycin A laden microparticles and died, but bluegill and largemouth bass did not. Initial studies to test Antimycin A laden microparticles in experimental ponds with algal attractants showed that microparticles killed a number of the silver carp and bighead carp in the pond without killing largemouth bass. Options for field experiments are now being explored. USGS researchers are adapting use of microparticles for other toxicants, bioactive compounds, and to target grass carp and other invasive species.

\section{Algal Attractants}

USGS scientists have discovered that Asian carp are strongly attracted to certain mixtures of algae and have been testing methods for using the attractants as lures to facilitate fish conduct analyses to answer engineering questions and inform modeling efforts at Brandon Road Lock and Dam (BRLD) and other locations in the Illinois River and the Chicago Area Waterway System. Continuous flow and water-quality data contribute to designing Asian carp controls that are effective even when storms, lock operations, and other factors change water flow. The USGS and the USFWS also have conducted experiments in the Illinois Waterway to understand the potential for young Asian carp to move into areas not yet invaded, including beyond electric dispersal barriers. The USGS has measured and analyzed the hydrodynamics around the barges and provided the information to managers that are working on mitigation strategies.

\section{Carbon Dioxide}

The results of laboratory studies and other research in experimental ponds suggest that silver carp and bighead carp avoid areas with elevated concentrations of carbon dioxide gas capture and removal. In expanded studies, algal compounds favored by Asian carp are being applied as an attractant through "feeding stations" deployed in conjunction with nets and traps. The attractants help draw Asian carp toward nets, traps, and other capture gear. The effectiveness of the gear for harvesting fish is then evaluated. Other studies involve the pairing of underwater sound with algal attractants to see how that combination affects Asian carp responsiveness to feeding stations, and testing the use of feeding stations for enhancing fish attraction during microparticle application.

\section{Underwater Sound}

The USGS is testing the use of underwater sounds to deter further spread of Asian carp. Working with the University of Minnesota, the USGS determined that bighead carp and silver carp react strongly to the broadband outboard-motor sound. Bighead carp and silver carp swam away from the recorded sound of a boat motor as many as 37 times in succession, whereas many 


\section{Creating Barriers — Stopping Asian Carp at Brandon Road Lock and Dam}

In the Great Lakes Mississippi River Interbasin Study, the U.S. Army Corps of Engineers (USACE) is assessing the viability of establishing a single point to control the one-way, upstream transfer of Asian carp and other aquatic nuisance species from the Mississippi River Basin into the Great Lakes Basin near the Brandon Road Lock and Dam (BRLD) located in Joliet, Illinois. The USGS is providing critical hydraulic data and analyses to help the USACE understand water flow and quality around the BRLD and inform barrier decisions, and to provide information for testing control tools.

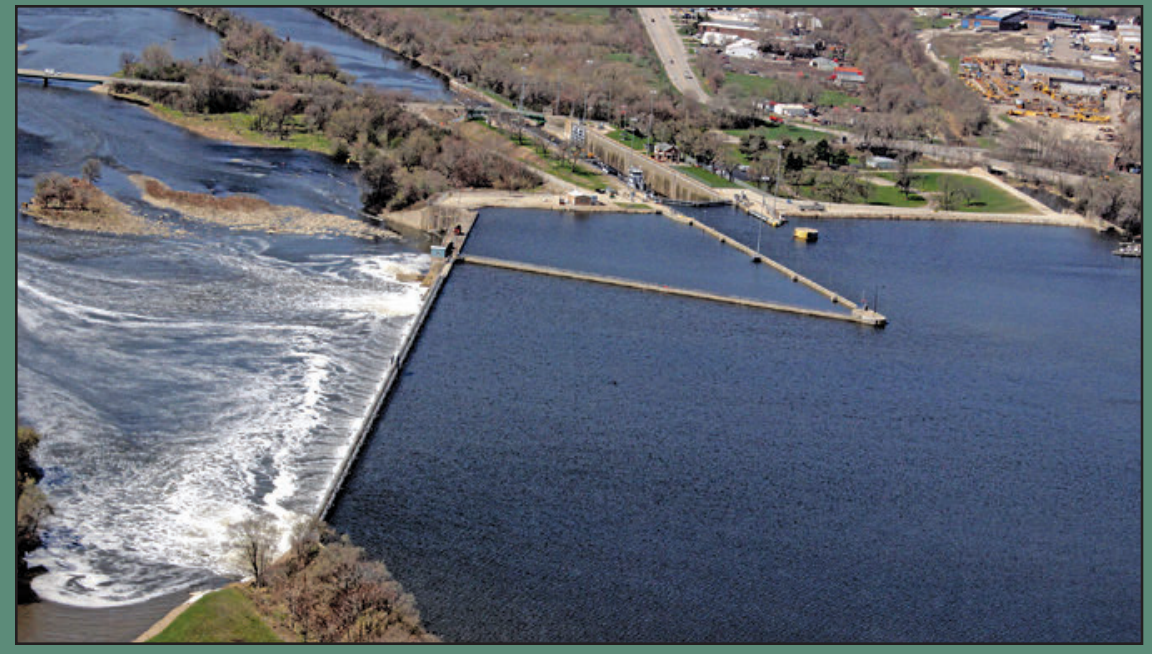

Brandon Road Lock and Dam has been identified by the USACE as a downstream control point of the Chicago Area Waterway System for Asian carp and a number of other aquatic nuisance species. The topographic and geographic positioning of the site allows it to serve as a single point of passage for species able to move upstream toward the Great Lakes. (Photograph by U.S. Army Corps of Engineers, April 22, 2014.)

native fishes had little to no response. This suggests that sound may have some specificity for bighead carp and silver carp, and deter them from entering an area while allowing native fishes to move freely. Studies also are underway to evaluate the use of sound to move fish and improve capture and removal.

\section{Making New Detection and Control Tools} Available for Use

As new tools are developed, managers need information about how the tools work, the information they provide, and how to use them. The USGS works with resource managers to better understand the Asian carp issues that managers want to address. The USGS also leads training sessions and workshops to meet managers' needs and to introduce new tools, technologies, and scientific findings. them where they now occur, including the Ohio River and Mississippi River Basins. Contributions by the USGS to inform integrated pest management are particularly important, especially the objective evaluation of tools for control. The USGS will continue this important research, coupled with education, synthesis, publication, and other forms of knowledge transfer that inform management solutions.

\section{Reference Cited}

Murphy, E.A., Garcia, Tatiana, Jackson, P.R., and Duncker, J.J., 2016, Simulation of hypothetical Asian carp egg and larvae development and transport in the Lockport, Brandon Road, Dresden Island, and Marseilles Pools of the Illinois Waterway by use of the fluvial egg drift simulator (FluEgg) model: U.S. Geological Survey Open-File Report 2016-1011, 19 p., http://dx.doi. org/10.3133/ofr20161011.

The USGS, in collaboration with the Great Lakes Restoration Initiative and Asian Carp Regional Coordinating Committee, provides science and technology to control the spread of Asian carp.
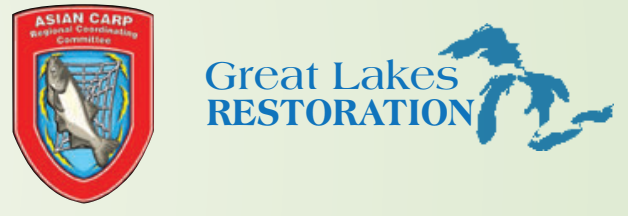

Authors:

Cynthia S. Kolar and Sandra S. Morrison

Carp images used in banner:

(C)Joseph R. Tomelleri. Used with permission. All other photographs from USGS unless otherwise noted. regulations is a major management consideration when applying chemical or biological control tools in any water body. To address environmental regulations, the USGS is collaborating with the USFWS and the EPA to develop the information needed to register chemical controls like $\mathrm{CO}_{2}$ and Antimycin A laden microparticles with the EPA and State regulatory agencies. The USGS and USFWS also are working to identify species for testing to assess potential effects of chemical or biological controls on threatened and endangered species.

\section{The Future}

The negative effects of invasive Asian carp in North America already are far reaching and have real potential to expand and intensify. A wide variety of organizations are working to keep these invasive fish out of the Great Lakes and other aquatic ecosystems and control

\section{For more information:}

\section{Ecosystems Mission Area http://www.usgs.gov/ecosystems/ http://www.usgs.gov/ask/ 1-888-ASK-USGS (1-888-275-8747)}

USGS Asian carp science - https://www2.usgs. gov/ecosystems/invasive_species/midwest.htmIhttp://cida.usgs.gov/gIri/index.jsp\#/Home/AsianCarp

Great Lakes Restoration Initiative http://greatlakesrestoration.us

Asian Carp Regional Coordinating Committee http://www.asiancarp.us

National Asian Carp Plan http://anstaskforce.gov/Documents/Carps_ Management_Plan.pdf 1-888-ASK-USGS (1-888-275-8747)

Publishing support provided by the U.S. Geological Survey,

Science Publishing Network, Tacoma Publishing Service Center Design: William Gibbs 